\title{
Occupational injuries and diseases among commercial fishers in Finland 1996-2015
}

\author{
Kim 0. Kaustell, Tiina E.A. Mattila, Risto H. Rautiainen
}

Natural Resources Institute Finland, Helsinki, Finland

\begin{abstract}
Background: Commercial fishing is recognised as one of the most hazardous professions worldwide. In Finland, commercial fishing has some special characteristics, including fishing on ice during frozen waters, and pluriactivity of the fisher family to gain additional income. The goal of this study was to describe injury characteristics among commercial fishers in Finland during the years 1996-2015. With this information, we wish to promote creation of effective safety campaigns and interventions.

Materials and methods: The data for this study was acquired from The Farmers' Social Insurance Institution, who handles the mandatory pension and occupational injury insurance of Finnish commercial fishers. Descriptive statistics was used to categorise and analyse the data that comprised the anonymised insurance history of 1954 insured fishers and reports on 1135 compensated injuries, 11 fatalities, and 53 occupational disease cases.

Results: The results show, that the injury rate of Finnish commercial fishers is high. Forty per cent of the fishing-related injuries occur aboard or when entering or leaving the vessel, while $37 \%$ happened ashore, and $11 \%$ on sea or lake ice. The most common type of incident is preceded by a slip, trip, or sway followed by a fall to lower level. The injuries result in a median disability length of 21 days. An elevated risk for Finnish (vs. Swedish) speaking, as well as for male fishers was found. The occupational diseases of the studied population were for the most part results of manual, repetitive and/or physically straining work due to e.g. hauling in fishing equipment. Due to small numbers and lack of case data, it is not possible to make any further analysis of the 11 fatalities, which were all drownings.

Conclusions: Based on our findings, injury prevention should be targeted, besides preventing fatalities because of drowning, at mitigating the risks for slips, trips, and falls both aboard and ashore.
\end{abstract}

(Int Marit Health 2016; 67, 3: 163-170)

\section{Key words: commercial fishing, occupational safety, occupational disease}

\section{INTRODUCTION}

Commercial fishing is hazardous compared with most other occupations [1, 2]. Fishing has long traditions in Finland, but hard physical work in varying weather conditions, unpredictable catch, economic pressures, and strict governmental controls have made this old profession less attractive in recent years. While Finnish commercial fishing has unique economic structure and challenges, analysis of longitudinal national occupational injury and disease data can contribute to better understanding of the risks and opportunities for prevention.
The number of registered fishers in Finland has decreased from 3943 in 1998 to 2473 in 2014 [3, 4]. Most of the full-time and part-time fishers (accounting for 25\% and $75 \%$ of registered commercial fishers, respectively) fish perch, white fish, and pike perch in coastal water areas with nets and fyke-nets. Fishing vessels are typically small; the share of registered vessel less than $12 \mathrm{~m}$ in length has been over $92 \%$ (97.6\% in 2014) in coastal and offshore areas in recent years [3]. Only a small number of fishers and vessels are involved in fishing Baltic herring in open sea areas; however, it is the most important catch in 


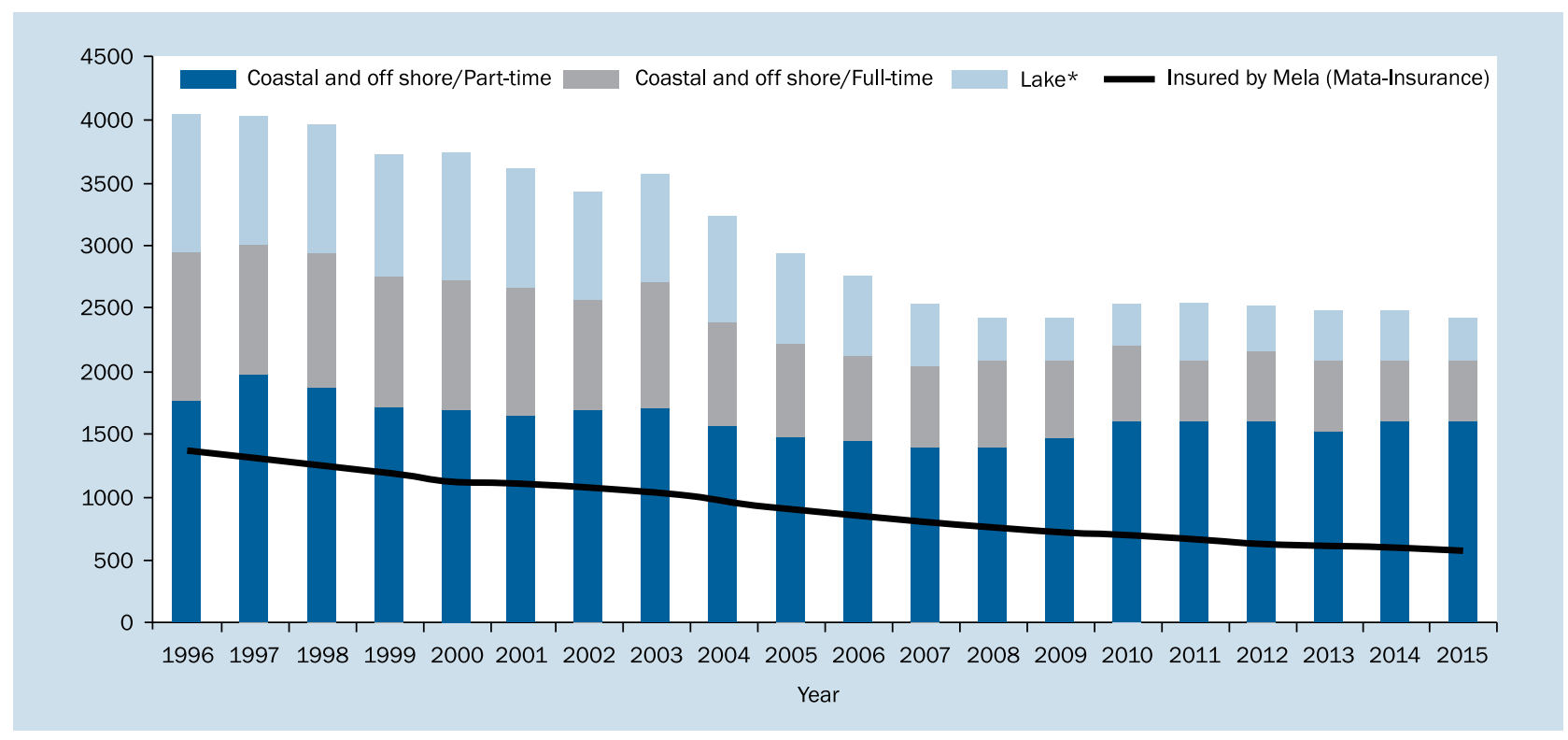

Figure 1. Number of registered commercial fishers by fishing area and occupation type, and the number of Mata-insured commercial fishers; *Census of commercial fishers on lakes is done bi-annually as of 1998 , and the numbers between census years have been interpolated (1999-2013) and linearly extrapolated (years 1996, 1997 and 2015)

Finland. The economic value of the Baltic herring catch was 23 million euro in 2015. The total fish catch of commercial fishers from sea areas was 148 million $\mathrm{kg}$, valued at 37 million euro in 2015 [3].

While fishing is known to have high occupational fatality rates, there is lack of specific information, particularly on non-fatal injuries. A better understanding of the working environment and injury risks is needed to create effective safety campaigns and interventions. To address this gap, the aim of this study was to describe injury characteristics among commercial fishers during the past 20 years in Finland.

\section{MATERIALS AND METHODS}

The data for this study were acquired from the Finnish Farmers Social Insurance Institution's (Mela) accident insurance (Mata) database. These data comprised demographic information on all Mata-insured fishers during the years 1996-2015. The Mata insurance is mandatory for fishers and their family members if they pay tax from their fishing income and if their income from fishing is at least 3779 euro per year (2016 level). During the period 1998-2014, $32-24 \%$ of all commercial fishers were covered by the Mata insurance (Fig. 1) [5].

The Mata insurance system does not cover small scale commercial fishing, fishing outside of the territorial waters of Finland, and most of fish farming. Comprehensive insurance and occupational injury data of the whole professional fisher population are not available, because many are insured as farmers, fish processing entrepreneurs, or other, and are thus not included in the data source available for this study.
The data comprised a total of 1954 people who were insured as fishers during the years 1996-2015. Of these, 535 suffered one or more injuries, for a total of 1135 compensated injuries and 11 fatalities. The claims data also included 53 occupational disease cases that were diagnosed in 27 insured people. Due to missing data on injury details, or lack of explicit connection of the injury to commercial fishing, 303 injury cases were rejected from the original injury data. The final injury data analysed in this study thus comprises compensated injury claims for 844 injuries and 41 occupational diseases. Among the injuries, there were 11 fatalities.

The anonymised data included information on age, gender, and mother tongue of the insured; home and injury locations, income and insurance period details, injury date, work task during injury, contact mode, specific physical activity, deviation from usual course of work, material agent, injured body part, type of injury, ICD-10 diagnosis code, disability duration, as well as a short (up to 432 characters) description of the incident or exposure. Numeric and coded data were used for descriptive statistics, and incident descriptions were analysed and categorised for additional insight into causation. Basic calculations were made using Microsoft Excel 2010. SAS Enterprise Guide v. 7.11 software was used for additional analysis [6].

The social insurance data from Mela does not include information on person-work-years, nor does it distinguish between full- or part-time occupation fishers. To be able to estimate the injury rate (number of injuries per person-work-years), the main vs. part-time ratio for the Mata- 


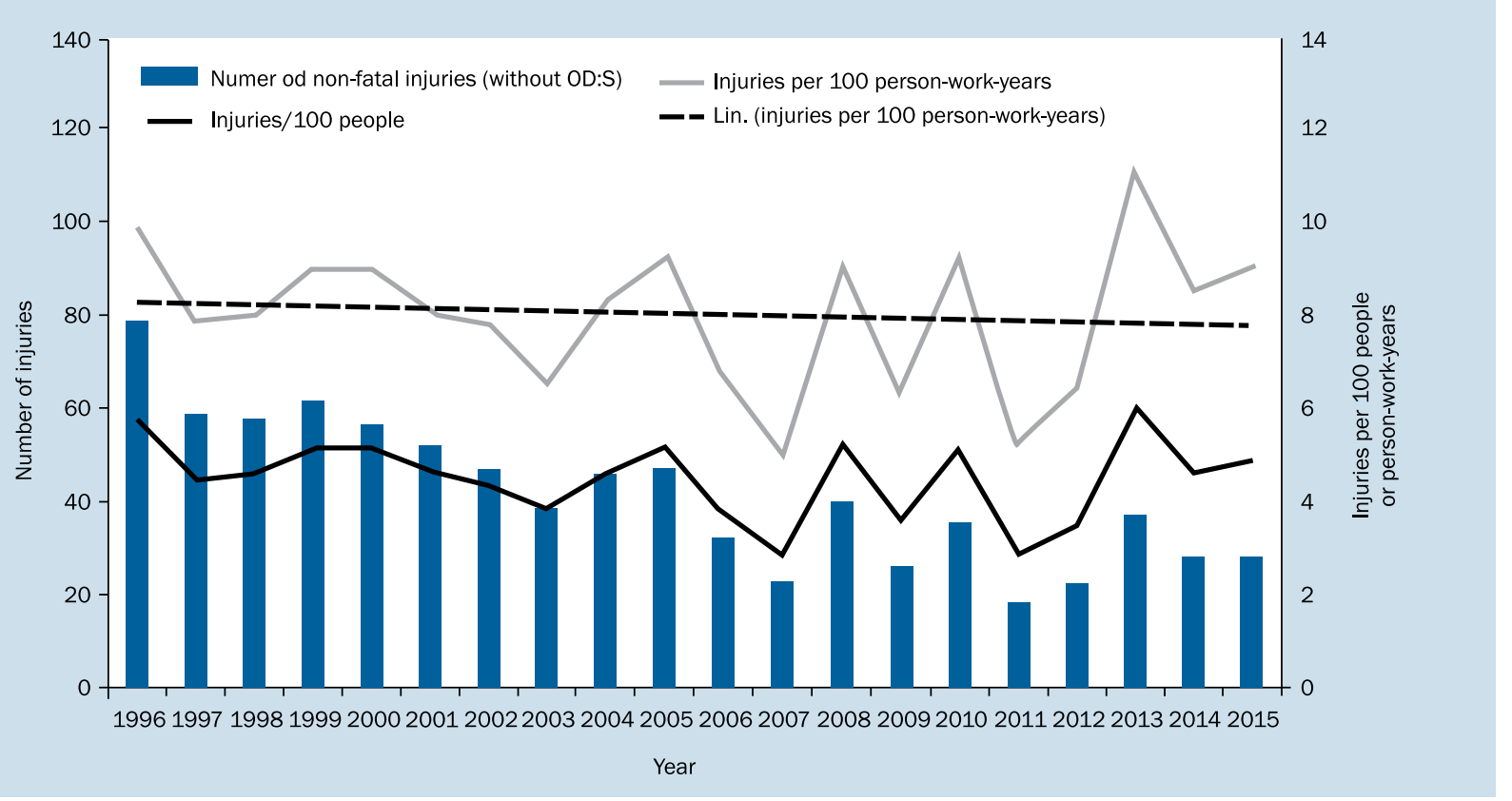

Figure 2. Yearly number of injuries and injury rates per 100 people and person-work-years

-insured people was estimated using the ratio indicated in the register of all commercial fishers [3, 4]. The calculation of person-work-years is based on the assumption of full time fishers accounting for 0.9 person-work-years per year, and part time occupation fishers accounting for 0.45 personwork-years per year, as used in [7].

\section{RESULTS}

\section{STUDY POPULATION}

The study population comprised 1954 insured people (1659 or $85 \%$ male), of which 439 suffered one or more injuries and 20 were diagnosed having one or more occupational diseases during the period.

In the study population, the mean age at time of injury was 47.6 years with an increasing linear trend of 0.43 $\left(r^{2}=0.76\right)$ years per year during the observed period. Correspondingly, the mean age for the insured population was 48.3 years over the entire study period, with a yearly linear increase of 0.25 years of age per calendar year $\left(r^{2}=0.93\right)$. The age distribution of the injured fishers ranges from 21 to 73 . Most (38\%) of the injuries happened to fishers in the age category from 45 to 54 years. The injured had from 0 to 41 years of experience as fishing entrepreneurs, with a median of 14 years and average 14.9 years. Four of the 844 injuries occurred to family members of the insured fisher, while doing fishing-related work.

Finland is a bi-lingual country, and the majority of the Swedish-speaking population resides in coastal areas. In the study population, 668 or $34 \%$ of the insured fishers were Swedish speaking. In the whole population of Finland, the share of Swedish speaking population was 5.5\% in year 2005 [8].

\section{NON-FATAL INJURIES}

There were a total of 833 non-fatal, fishing-related occupational injuries that occurred to 439 insured fishers during the observed period. Most of the injured people (59\%, or 259) suffered just one injury during the observed period while $41 \%$ or 178 people were injured two or more times. The two most frequently injured fishers had 13 and 16 fishing-related injuries during the observed period.

The estimated average injury rate was 7.9 injuries per 100 person-work-years, or 4.5 injuries per 100 insured people. Both rates have a slight, although not statistically significant, downward trend over the observed period (Fig. 2).

Most (401 or $91 \%$ ) of the injured fishers were male. As $85 \%$ of all insured fishers were males, they had 2.2 times greater odds of injury (95\% confidence interval 1.5-3.1) compared with females.

A total of 198 (24\%) of the injuries happened to Swedish speaking fishers, while the share of Swedish speaking fishers among all insured fishers is 34\%. The odds for being injured were 1.5 times greater for the Finnish speaking fishers (vs. Swedish speaking) (95\% confidence interval 1.2-1.9).

Based on the injury descriptions, $40 \%$ of all fishing-related injuries occurred on fishing vessels/boats or during boarding/exiting the vessel/boat. The rest occurred ashore, on sea or lake ice during winter fishing activities, or the location was not reported (Fig. 3). 


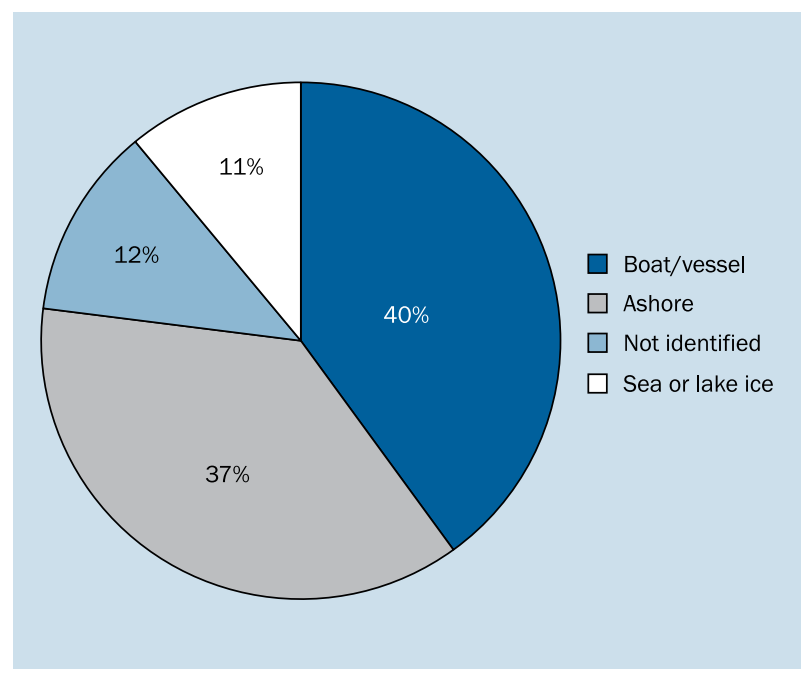

Figure 3. Location of injury incidents

Table 1. Work tasks during injury

\begin{tabular}{lll}
\hline Working process & N & Per cent \\
\hline Maintenance and repair of equipment & 168 & $20.2 \%$ \\
Fish handling, transport and storage & 136 & $16.3 \%$ \\
Other specific fishing work $^{*}$ & 126 & $15.1 \%$ \\
Trawling $^{*}$ & 101 & $12.1 \%$ \\
Other unclear or unspecified fishing work $^{*}$ & 84 & $10.1 \%$ \\
Commuting to or from the fishing vessel $^{*}$ & 65 & $7.8 \%$ \\
Fishing with nets $^{*}$ & 61 & $7.3 \%$ \\
Fishing with drag nets $^{*}$ & 33 & $4.0 \%$ \\
Fishing with fyke nets & \\
Other & 26 & $3.1 \%$ \\
\hline
\end{tabular}

${ }^{*}$ Actual fishing processes, including winter fishing on ice

Actual fishing processes with different kind of equipment accounted for $42 \%$ of the injuries. The most frequent work tasks during the time of the incident involved maintenance and repair of equipment (20\%), followed by fish handling, transport and storage (16\%) (Table 1). Most of the "fish handling, transport and storage" (65\%), "commuting to/from the vessel" (59\%), and "equipment maintenance and repair" (57\%) related injuries happened ashore. The injured people were moving around (e.g. walking, running or climbing) without a load in 14\%; manually handling objects (e.g. catching, grasping, tying or opening/closing doors or hatches) in 10\%; and moving objects manually (e.g. lifting, pushing, pulling loads) in $9 \%$ of the cases.

The abnormal event (deviation) that led to half of all fishing related injuries was slip, sway or trip leading to fall (STF) to lower (30\%) or same (20\%) level (Table 2). Slippery terrain or ice was associated with STF-related injuries in $28 \%$
Table 2. Deviations that led to injuries

\begin{tabular}{|c|c|c|}
\hline Deviation & $\mathbf{N}$ & Per cent \\
\hline $\begin{array}{l}\text { Slips, trips, sways and falls to same or } \\
\text { lower level }\end{array}$ & 416 & $49.9 \%$ \\
\hline Body movements without physical load & 102 & $12.2 \%$ \\
\hline $\begin{array}{l}\text { Loss of control of unspecified machine, } \\
\text { vehicle, or object }\end{array}$ & 86 & $10.3 \%$ \\
\hline Surprise, getting upset, violence & 37 & $4.4 \%$ \\
\hline Body movement under physical stress & 56 & $6.7 \%$ \\
\hline Break, collapse or fall of object or structure & 54 & $6.5 \%$ \\
\hline Electrical disturbance, explosion, fire & 4 & $0.5 \%$ \\
\hline Other or not known & 78 & $9.4 \%$ \\
\hline
\end{tabular}

of the STF cases. The corresponding figures were $22 \%$ for "Floor, aisle, deck, doorstep", 7\% for "Boat or vessel", and $5 \%$ for "Fishing gear and equipment".

Most injuries (56\%) were caused by horizontal or vertical impact with or against a stationary object. Being struck by or colliding with a moving object led to an injury in $10 \%$ of the cases, while stress on the musculo-skeletal system caused $9 \%$ of all injuries. The injured part of body was typically upper extremities (44\%), lower extremities (23\%) or back, including spine and vertebra in the back (17\%). Head trauma accounted for $6 \%$ of all injuries.

The most common types of injuries were dislocations, sprains and strains (40\%), wounds and superficial injuries (25\%), bone fractures (16\%), and concussions and internal injuries (16\%). The remaining injury types represent frequencies smaller than $2 \%$.

The severity of the injuries is reflected in the length of disability. The average number of days lost per injury, excluding occupational diseases, was 82.7 days, while the median was 21 days (Fig. 4). Calculated in calendar years, on average 8.6 years of working time were annually lost due to injuries during the study period.

\section{FATALITIES}

There were 11 fatalities during the period, fluctuating from 0 to 3 (in 2007) per year, resulting in a fatality rate of 1.06 per 1000 calculated person-work-years. All fatal injuries were drownings, although the person may have also suffered secondary injuries. All victims were men with a mean age of 42 years. Particular causes or chains of events that lead to these fatalities are not known. Storm was mentioned in two injury descriptions, and in two cases, the incident happened when manoeuvring/moving the boat in harbour. Seven happened in October or November, one in February and three in April/May, all during open waters (not during fishing on ice). 


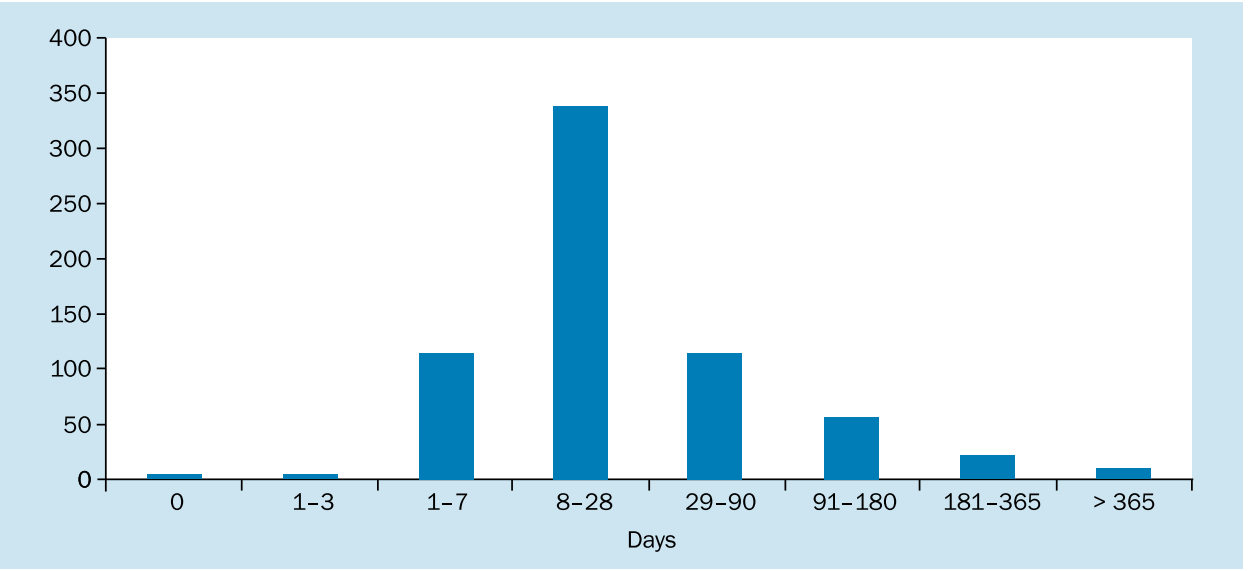

Figure 4. Frequency of injuries by length of disability

Table 3. Occupational diseases of fishers in 1996-2015

\begin{tabular}{|c|c|c|c|}
\hline Diagnosis & ICD-10 & $\mathbf{N}$ & Example of injury description \\
\hline $\begin{array}{l}\text { "Tennis elbow" and other } \\
\text { enteropathies, infective bursitis }\end{array}$ & $\begin{array}{l}\text { M77 } \\
\text { M771 } \\
\text { M779 } \\
\text { M711 }\end{array}$ & 18 & $\begin{array}{l}\text { During net fishing and because of high wind, I was forced to exceptionally hard } \\
\text { lifting of nets into the boat by hand. During a couple of days of storm, my left } \\
\text { hand got sore because of lifting work. }\end{array}$ \\
\hline Synovitis and tenosynovitis & $\begin{array}{l}\text { M65 } \\
\text { M658 }\end{array}$ & 14 & $\begin{array}{l}\text { Ice was thicker than normal during winter } 1999 . \text { I had to use an ice pick to make } \\
\text { more holes than usually, and with harder work, for more than one hundred spring } \\
\text { hooks and } 60 \text { nets. My left hand became overstrained and got sore. I went to } \\
\text { a doctor one month later. }\end{array}$ \\
\hline $\begin{array}{l}\text { "Mole fever", other viral } \\
\text { haemorrhagic fevers }\end{array}$ & A98 & 3 & $\begin{array}{l}\text { N.N. had sudden high fever and muscle pain. Diagnosis: mole fever. Possible } \\
\text { infection source repairing fishing equipment in a barn, where above-mentioned } \\
\text { equipment was stored. }\end{array}$ \\
\hline $\begin{array}{l}\text { Soft tissue disorders related to } \\
\text { use, overuse and pressure }\end{array}$ & M700 & 2 & $\begin{array}{l}\text { I was line fishing. I hauled in the snoods by hand for eight hours. My left hand got } \\
\text { sore and swelled. }\end{array}$ \\
\hline $\begin{array}{l}\text { Effects of vibration, "White finger } \\
\text { syndrome" }\end{array}$ & $\mathrm{T} 752$ & 2 & $\begin{array}{l}\text { Fingers become white, cold and get pain in cold conditions. This happens when } \\
\text { weather has been cooling down. Hands are cold for a long time. The situation has } \\
\text { slowly been getting worse and stopped winter fishing. }\end{array}$ \\
\hline Irritant contact dermatitis & L248 & 2 & A rash broke out when I was processing fish. \\
\hline
\end{tabular}

\section{OCCUPATIONAL DISEASES}

There were 41 fishing-related occupational disease cases in the 20-year data. Seven of these were diagnosed in women and 34 in male fishers. Occupational diseases were most typically caused by physically hard, repetitive or unfamiliar work tasks or working postures, or sudden, straining movements. Also harsh/cold weather conditions were mentioned in the short incident descriptions. ICD-10 code 711, Lateral epicondylitis, or "Tennis elbow" [9]) alone covers one third, or 14, of the occupational disease diagnoses (Table 3).

\section{DISCUSSION}

The number of commercial fishers in Finland has decreased while their mean age has increased. Even though the injury rate has a slight downward trend, the rate is still almost twice as high compared with all salaried occupations (4.5 vs. 2.6 injuries per 100 people). The injury rate found in this study is in accordance with that of the broader combined class "Agriculture, forestry, and fishing" reported in the national statistics [10]. The rate $(4.5 / 100)$ for the observed fisher population is based on fishing-related injuries only. Considering the pluriactivity of the typical Finnish fishers and accounting for both fishing and non-fishing-related injuries in the observed fisher population, the injury rate was 6.1 per 100 person-years. This is similar to the injury rate for Finnish agriculture reported by Karttunen and Rautiainen [11].

The odds of injury were more than twice as high in males compared with females. This difference is likely influenced 
by the division of work tasks and fishing-related working hours by gender. It is also noteworthy, that mother tongue of the insured fishers had a significant association with the odds of injury, likely due to under-reporting among Swedish speaking fishers. A similar potential underreporting of injuries has also been observed in Finnish farmers [11-13]. The reasons for the difference in injury risk for both gender and mother tongue would require further studies.

Traditionally, in addition to actual fishing, Finnish fishers also conduct fishing-related work ashore, such as processing fish and transporting it to market as well as maintenance and repair of boats, equipment and structures/buildings for these activities. Only $40 \%$ of the injuries were directly connected to work on fishing vessels. Little attention has been paid to accidents that occur when vessels are in the harbour, as stated by Le Bouar and Chauvin [14]. They noticed that about $30 \%$ of all registered injuries in the fishing industry in France occurred in these situations.

Sea and lake fishing in Finland differs from most other countries in wintertime due to several months of ice cover. Injuries suffered on ice while fishing or commuting to/from the fishing site comprised 97 or $11.6 \%$ of all observed cases. In 12 cases the injury was the result of losing control of a snowmobile while riding on uneven ice.

In the observed period, 168 or $20 \%$ of the injuries happened when the insured person was e.g. mending or tuning fishing gear, repairing the landing, or fixing the boat. Maintenance and repair work has been recognised to be one of the most hazardous working processes in agriculture as well $[15,16]$. Suspected reasons for this are limited resources to make safety improvements, the slow incremental evolution of the physical working environment where old hazardous structures remain long in place, and also some personal characteristics of farmers [17].

Slips, trips and sways that lead to fall, and result in an injury, are the most common deviation type in most occupational injury studies. Jensen [18] studied injuries in Danish fish landings/harbours, and found that $25 \%$ of the injuries were results of this type of deviation. Antão et al. [19] found the corresponding figure for the Portuguese fishing sector to be $28 \%$. In this study, STF injuries represent almost one half of the incidents, but when limited to only vessel/boat-related incidents, the figure was $23 \%$.

Severity and economic significance of injuries can be estimated by analysing lengths of disability. In this study, the median of days lost due to injury was 3 weeks. There is great variation in the length of compensated disability even within similar injury type/diagnosis. The economic significance of the injury and disability time on the business of the fisher also depends on whether or not the disability coincides with high season for catching fish.
The annual number of fatal injuries appears to have decreased during the observed period. The latest fatal injury occurred in 2007 . Four additional fishing fatalities during the studied period could be found in investigation reports published by the Safety Investigation Authority [20]. These happened to fishers for whom the Mata insurance is not mandatory and who thus were not among the studied population.

Due to small numbers and annual variation, it is not possible to conclude if the reduction in the frequency of fatalities is statistically significant. Jensen et al. [21] compared fatal injury trends in 8 northern areas/countries and also found mainly decreasing trends of the fatal injury incidence rates from 1980 to 2010. They stated that small vessels have a highest risk. The fatality rate of 1.06 per 1000 person-work-years calculated in this study, as well as the main causes (vessel disasters and drowning) are well in accordance with the findings of Jensen et al. [21].

The Mata insurance compensates occupational diseases in addition to injuries. The compensable diseases are defined in law, similar to workers' compensation insurance rules for other occupations. Manual, repetitive and/ /or physically straining work exposes fishers to cumulative trauma and soft tissue outcomes. Other outcomes included haemorrhagic fever (likely from exposure to rodents), irritant contact dermatitis (from processing fish), and white finger (from vibration exposure).

Commercial fishing in Finland is typically on a smallscale and seasonal, which leads to the need for additional income from other employment. Farming, various services, and salaried work, along with small scale fish processing and sales are some of the most common additional ways of earning supplemental income [22]. If possibilities for other income are limited in the area, it will put high stress on getting a good catch during the season, which can be short. In practice this means very long working hours, fatigue and safety risks during the season. Fatigue has been found to be a serious health and safety problem among fishers [23]. In this study, it could not be determined if stress, fatigue, and sleep deprivation contributed to the injuries. While it is likely, further studies would be needed to investigate their contribution.

\section{LIMITATIONS OF THE STUDY}

The social insurance injury claims data used in this study only covers approximately $25 \%$ of the commercial fishers. However, these data may cover most active fishers as minimum income for the mandatory insurance is low; 3779 euro per year from fishing. In addition, our data misses commercial fishing outside Finnish territorial waters. This complicates statistical assessment and interpretation of 
occupational injuries and diseases related to the fishing profession as a whole in Finland. There is also a possibility of non-fishing related injuries being included due to the supplemental occupational activities among fishers, even if these were carefully removed based on the injury descriptions.

Injury claims data used in this study may be subject to underreporting, which can undercount the total number of injuries, minor injuries in particular. The data can also include some injury claims that have been filed or classified incorrectly.

\section{CONCLUSIONS}

Finnish commercial fishers are an ageing and diminishing population. Similar to their peers in other countries, they have a high risk of occupational injuries. Special characteristics of the fishing industry in Finland include pluriactivity and fishing on ice. As much of the fishing-related activity happens ashore, it is important to focus on injury sources in all work tasks, not only actual fishing and fishing vessels. Besides fatalities from drowning, a major focus in prevention should be on reducing slips, trips, and falls from elevation, both aboard and ashore. Mitigation of effects of slipperiness deserves special attention. Further, proper use of snowmobiles, especially when riding in poor visibility, or on ice, should be promoted.

Vocational training and occupational health services for fishers could be ways to promote health and safety. Increasing age of commercial fishers, as well as some expressed opinions, point out that fishing is not a very attractive profession among young people. This can reduce and slow down the effect of vocational training on mitigating injuries. Occupational health services including regular health checks and workplace safety screenings are mandatory only for hired workers, whereas the fishers in Finland are mostly self-employed. Only $13 \%$ of the studied population had joined the occupational health services. To be effective, these services should be designed and offered in a way to attract significantly more fishers.

Based on injury statistics, commercial fishing is recognised as a relatively dangerous profession in many studies. A comparison of injury rates between different occupations and countries is difficult due to different data reporting procedures and principles. Vessel size and type are a common classifier in reports dealing with injuries among fishers [2, 7, 21]. In Finland, more than ninety per cent of the boats used in coastal and offshore fishing are shorter than $12 \mathrm{~m}$. While less than half of the fishing related injuries happened on board or while entering/exiting the boat, it would still be beneficial for further investigations to record the vessel length and type along with other details of the incident.

\section{ACKNOWLEDGEMENTS}

This study was supported by The Nordic Council of Ministers, and Natural Resources Institute Finland. The Farmers' Social Insurance Institution (Mela) provided the injury data for the study.

\section{REFERENCES}

1. U.S. Bureau of Labor Statistics. Hours-based fatal injury rates by industry, occupation, and selected demographic characteristics, 2014. [cited June 18, 2016]; Available at: www.bls.gov/iif/oshwc/ cfoi/cfoi_rates_2014hb.pdf

2. McGuinness E, Aasjord HL, Utne IB, Holmen IM. Injuries in the commercial fishing fleet of Norway 2000-2011. Safety Sci 2013; 57: 82-99.

3. Official Statistics of Finland: Commercial marine fishermen. Natural Resources Institute Finland, Helsinki. [cited June 14, 2016]. Available at: www.stat.luke.fi/en/commercial-marine-fishery

4. Official Statistics of Finland: Commercial inland fishermen. Natural Resources Institute Finland, Helsinki. [cited June 14, 2016]. Available at: www.stat.luke.fi/en/commercial-inland-fishery

5. Statistics of insured farm entrepreneurs at the end of year [in Finnish]. The Farmers' Social Insurance Institution Mela, Espoo, Finland 2016. [cited June 14, 2016]. Available at: www.mela.fi/en/

6. SAS Enterprise Guide v. 7.11 software. SAS Institute Inc., Cary, NC, USA. 2015

7. McGuinness E, Aasjord HL, Utne IB, Holmen IM. Fatalities in the Norwegian fishing fleet 1990-2011. Safety Sci 2013; 57: 335-351.

8. Official Statistics of Finland: Population according to language 1980-2015. Statistics Finland, Helsinki. [cited June 21, 2016]. Available at: www.stat.fi/til/vaerak/2015/vaerak_2015_2016-04-01_ tau 002 en.html

9. International statistical classification of diseases and related health problems. $10^{\text {th }}$ Revision. World Health Organization, Geneva. [cited June 16, 2016]. Available at: www.apps.who.int/classifications/ icd10/browse/2016/en

10. Official statistics of Finland: Occupational accident statistics. Statistics Finland, Helsinki. [cited June 16, 2016]. Available at: www. stat.fi/til/ttap/index_en.html

11. Karttunen JP, Rautiainen RH. Occupational injury and disease incidence risk factors in Finnish agriculture based on 5-year insurance records. J Agromedicine 2013; 18: 50-64.

12. Rautiainen RH, Ledolter J, Donham KJ, Ohsfeldt RL, Zwerling C. Risk factors for serious injury in Finnish agriculture. Am J Ind Med 2009; 52: 419-428.

13. Jadhav R, Achutanb C, Haynatzkic G, Rajaramd S, Rautiainen RH. Review and meta-analysis of emerging risk factors for agricultural injury. J Agromedicine 2016; 21: 284-297.

14. Le Bouar G, Chauvin C. An analysis of the risk in the French sea fishing industry. Example of the dockside accident risk. Int Marit Health 2006; 57: 103-113.

15. Karttunen JP, Rautiainen RH. Distribution and characteristics of occupational injuries and diseases among farmers: a retrospective analysis of workers' compensation claims. Am J Ind Med 2013; 56: 856-869.

16. Rasmussen $\mathrm{K}$, Carstensen $\mathrm{O}$, Lauritsen JM. Incidence of unintentional injuries in farming based on one year of weekly registration in Danish farms. Am J Ind Med 2000; 38: 82-89.

17. Kaustell KO, Mattila TEA, Rautiainen RH. Barriers and enabling factors for safety improvements on farms in Finland. J Agric Saf Health 2011; 17: 327-342. 
18. Jensen OC. Non-fatal occupational fall and slip injuries among commercial fishermen analyzed by use of the NOMESCO injury registration system. Am J Ind Med 2000; 37: 637-644.

19. Antão P, Almeida T, Jacinto C, Guedes Soares C. Causes of occupational accidents in the fishing sector in Portugal. Saf Sci 2008; 46: 885-899.

20. Marine investigation reports by year. Safety investigation authority, Helsinki, Finland. [cited June 16, 2016]. Available at: www.turvallisuustutkinta.fi/en
21. Jensen OC, Petursdottir G, Holmen IM, Abrahamsen A, Lincoln J. $A$ review of fatal accident incidence rate trends in fishing. Int Marit Health 2014; 65: 47-52.

22. Salmi P. Rural pluriactivity as a coping strategy in small-scale fisheries. Sociol Ruralis 2005; 45: 22-36.

23. Høvdanum AS, Jensen O, Petursdōttir G, Holmen IM. A review of fatigue in fishermen: a complicated and underprioritised area of research. Int Marit Health 2014; 65: 166-172. 